\title{
Corrigendum
}

\section{An Intronic Variant in OPRDI Predicts Treatment Outcome for Opioid Dependence in African-Americans}

\author{
Richard C Crist, Toni-Kim Clarke, Alfonso Ang, Lisa M Ambrose-Lanci, Falk W Lohoff, \\ Andrew J Saxon, Walter Ling, Maureen P Hillhouse, R Douglas Bruce, George Woody and \\ Wade H Berrettini
}

Neuropsychopharmacology (20 I4) 39, I039; doi:10.1038/npp.2013.304

Correction to: Neuropsychopharmacology (2013) 38, 20032010; doi:10.1038/npp.2013.99; published online 15 May 2013

In this article, in the first paragraph of the Discussion section, the fourth sentence (at the end of the right column of page 2007) should read: 'Conversely, African-American patients with the CC genotype had significantly BETTER opioid use outcomes when treated with methadone than individuals in the combined CT and TT genotypes group.' 